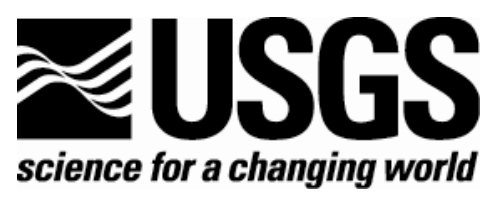

\title{
Zero-Headspace Coal-Core Gas Desorption Canister, Revised Desorption Data Analysis Spreadsheets and a Dry Canister Heating System
}

By Charles E. Barker and Todd A. Dallegge

\section{Open-File Report 2005-1177}

U.S. Department of the Interior U.S. Geological Survey 


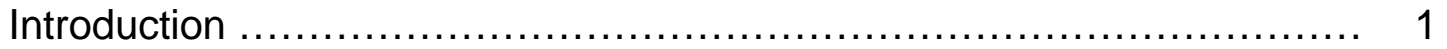

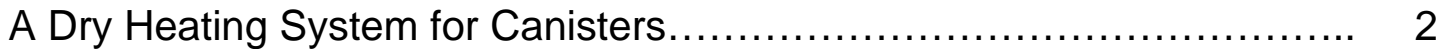

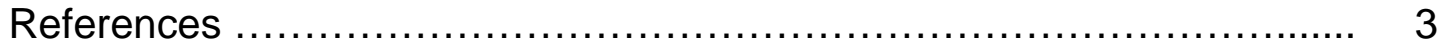

Links to revised spreadsheet and desorption data sheet $\ldots \ldots \ldots \ldots \ldots \ldots \ldots \ldots$

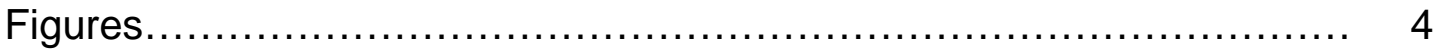

\section{Introduction}

Coal desorption techniques typically use the U.S. Bureau of Mines (USBM) canister-desorption method as described by Diamond and Levine (1981), Close and Erwin (1989), Ryan and Dawson (1993), McLennan and others (1994), Mavor and Nelson (1997) and Diamond and Schatzel (1998). However, the coal desorption canister designs historically used with this method have an inherent flaw that allows a significant gas-filled headspace bubble to remain in the canister that later has to be compensated for by correcting the measured desorbed gas volume with a mathematical headspace volume correction (McLennan and others, 1994; Mavor and Nelson, 1997). The USBM technique was adapted by Barker and others $(1991,2002)$ for use with polyvinyl chloride (PVC) plastic canisters and herein we redesign the canister so that essentially all headspace is purged of free gas by replacing it with water, thus making the headspace correction unnecessary. This design is based on a flexible neoprene cap on a PVC plastic pipe body (figs. 1,2). Coal core or cuttings are placed in the canister; which is subsequently filled with either distilled water or boiled and filtered formation water taken from a well and repeatedly tapped on a hard surface to get rid of the trapped bubbles inside. The canister is then fully immersed in a tank also filled with either sterile distilled water or local formation water that is sterilized by boiling or chemical methods. The neoprene canister cap is placed underwater and the trapped or attached bubbles removed by turning the cap over and brushing all surfaces while under the sterile water.

Our zero-headspace design has several advantages: (1) it reduces the amount of air mixed with the desorbed gas, thus reducing contamination of gas samples early in the desorption experiment; (2) the flexible rubber cap bulges as internal gas pressure rises indicating the canister should be measured, or it stretches inward indicating that a measurement should be avoided (because of the possibility of back-flow into the canister when canister pressure is less than atmospheric); and (3) it is made of materials that are resistant to attack by the acidic solution commonly generated in coal and water mixtures. A disadvantage of this zero-headspace design is that liquid from the completely water-filled headspace is easily introduced into the manometer hose during initial desorption 
measurements. This potential problem is remedied by adding a simple water trap into the manometer line (Fig. 3). Finally, a limitation of all PVC canisters is that the plastic pipe softens at $175^{\circ} \mathrm{F}$ and must be used at cooler temperatures. Because coal cores for CBM testing almost always come from a much lower formation temperature, the $175^{\circ} \mathrm{F}$ limitation is a minor constraint.

Using water to fill the canister headspace introduces water vapor into the gas stream emitted from the canister. If the water vapor content is large, a correction for the partial pressure of water may be necessary to precisely compute the final gas volume. However, Ryan and Dawson (1993) estimated that, at typical desorption experiment temperatures, a correction for water vapor results in only a small (a few percent) difference. Consequently, given the innate uncertainty in accurately determining the lost gas correction itself, the water vapor correction at low temperature can be considered negligible in most cases.

To take full advantage of this zero-headspace design, we have modified our published desorption data-analysis spreadsheet (Barker and others, 2002) to reflect zero headspace measurements (see link $A$ below), and also changed the basis for correcting measured volume data to standard temperature and pressure on a chemical basis $\left(0^{\circ} \mathrm{C}\right.$ or $32^{\circ} \mathrm{F}$ and $\left.1 \mathrm{~atm}\right)$ rather than the gas-engineering standard ambient temperature and pressure used previously (a temperature of $60^{\circ} \mathrm{F}$ and $\left.1 \mathrm{~atm}\right)$. This correction only affects the volume at STP column on the original sheet (Barker and others, 2002) and not the headspace-corrected volume that is actually used in resource calculations.

Measurement of the internal canister temperature using a thermocouple well, as shown in figures 4 and 5 , is not required in zero-headspace canister designs because internal temperature measresurements were only necessary for the headspace correction. Consequently, we have modified our spreadsheet and data-collection form (Links $B$ and $C$ below) by removing the input columns for internal canister temperature and thereby avoid confusion during data entry. The revised method still requires measurement of barometric pressure, ambient temperature and desorbed gas volume in the manometer.

Consistency in volume-measurement technique is also critical with the flexible cap design, because downward force on the cap during a measurement will tend to flex of the cap into the canister and push extra gas into the manometer line. Thus, the male quick connector on the hose to the manometer should be connected to the female connector on the canister and then held in a neutral position or released while the manometer is read.

\section{A Dry Heating System for Canisters}

For studies where a small, dry, portable canister heating system would be advantageous over the immersion-heater and water-tank method, we also designed a heat blanket system for heating zero-headspace canisters, as well as other types of coal desorption canisters to a constant temperature during the time when the lost gas correction is estimated (figs. 4,5 ). We have found this system to be useful for studies in remote locations that require a compact lightweight helicopter-portable system or in cases that involve only a few samples. However, this dry system is relatively expensive compared to heated water-bath systems. 


\section{References}

Barker, C.E., Johnson, R.C., Crysdale, B.L., and Clark, A.C., 1991, A field and laboratory procedure for desorbing coal gases: U.S. Geological Survey Open-File Report 91-563, $16 \mathrm{p}$.

Barker, C. E., Dallegge, T.A., and Clark, A.C., 2002, USGS coal desorption equipment and a spreadsheet for analysis of lost and total gas from canister desorption measurements: USGS web-based open File 02-496. http://pubs.usgs.gov/of/2002/ofr-02-496/

Close, J.C., and Erwin, T.M., 1989, Significance and determination of gas content data as related to coalbed methane reservoir evaluation and production implications: Proceedings of the 1989 Coalbed Methane Symposium, paper 8922, p. 37-55.

Diamond, W.P., and Levine, J.R., 1981, Direct method determination of the gas content of coal: procedures and results: U.S. Bureau of Mines Report of Investigations 8515, $36 \mathrm{p}$.

Diamond, W.P., and Schatzel, S.J., 1998, Measuring the gas content of coal: a review, in R.M. Flores, ed., Coalbed methane: from coal-mine outbursts to a gas resource: International Journal of Coal Geology, v. 35, p. 311-331

Mavor, M. and Nelson, C.R., 1997, Coalbed reservoir gas-in-place analysis: Gas Research Institute Report no. GRI-97/0263, 134 p.

McLennan, J.D., Schafer, P.S. and Pratt, T.J., 1994, A guide to determining coalbed gas content: Gas Research Institute, variously paginated.

Ryan, B.D. and Dawson, F.M., 1993, Coalbed methane canister desorption techniques, in Geological fieldwork 1993, B.C. Ministry of Energy, Mines and Petroleum Resources, Paper 1994-1, pages 245-256.

\section{Links}

A. Link to revised spreadsheet with internal temperature column (for zero-headspace measurements set headspace volume cell = zero and the internal temperature, $\mathrm{Ti}=\mathrm{Ta}$, the ambient temperature)

B. Link to Revised Spreadsheet without internal temperature column

C. Link to Revised Desorption data sheet without internal temperature column 
Figure 1. Design and construction details for a zero-headspace canister.

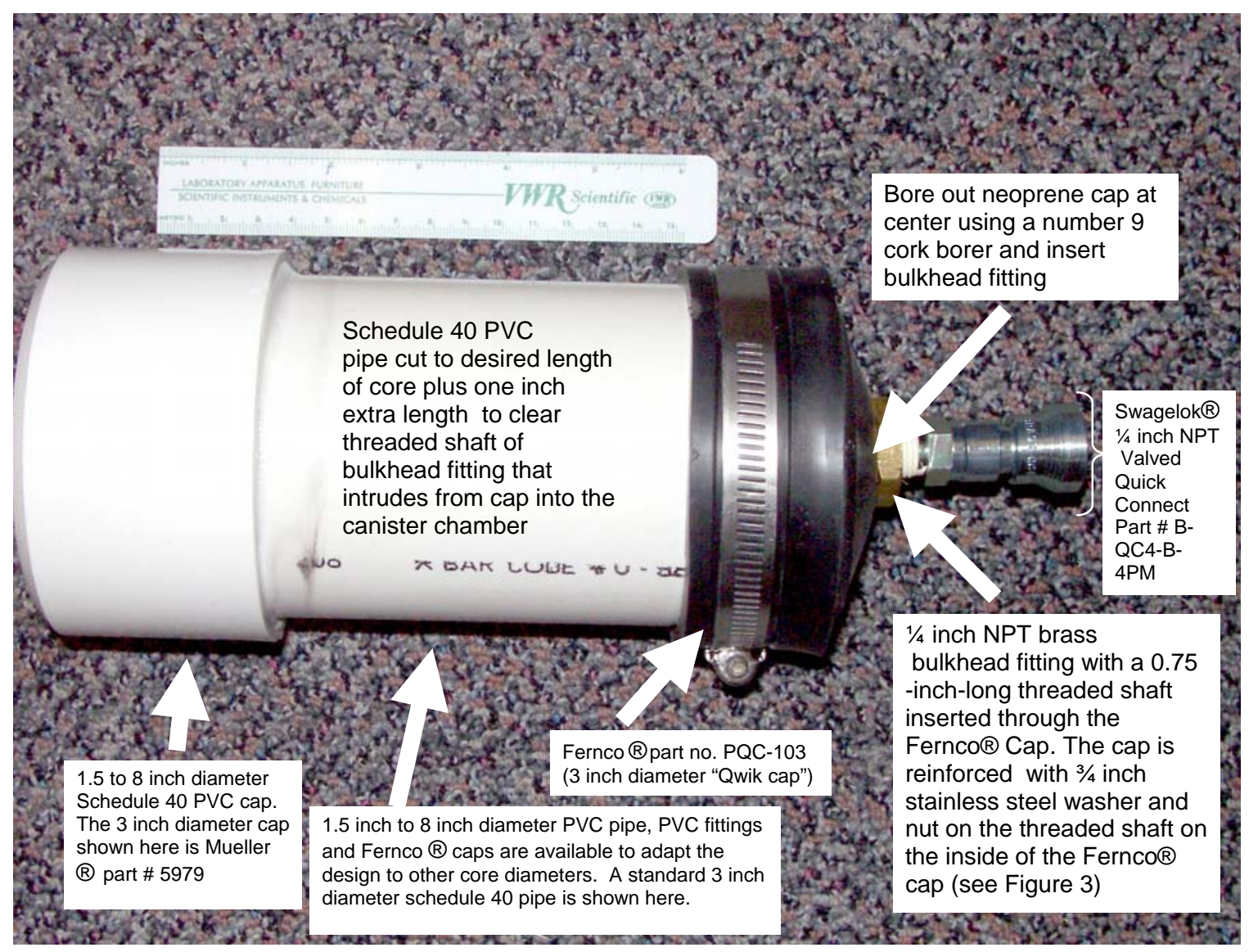


Figure 2. Design and construction details of the zero-headspace canister cap and beveled open pipe end that facilitates mounting the cap.

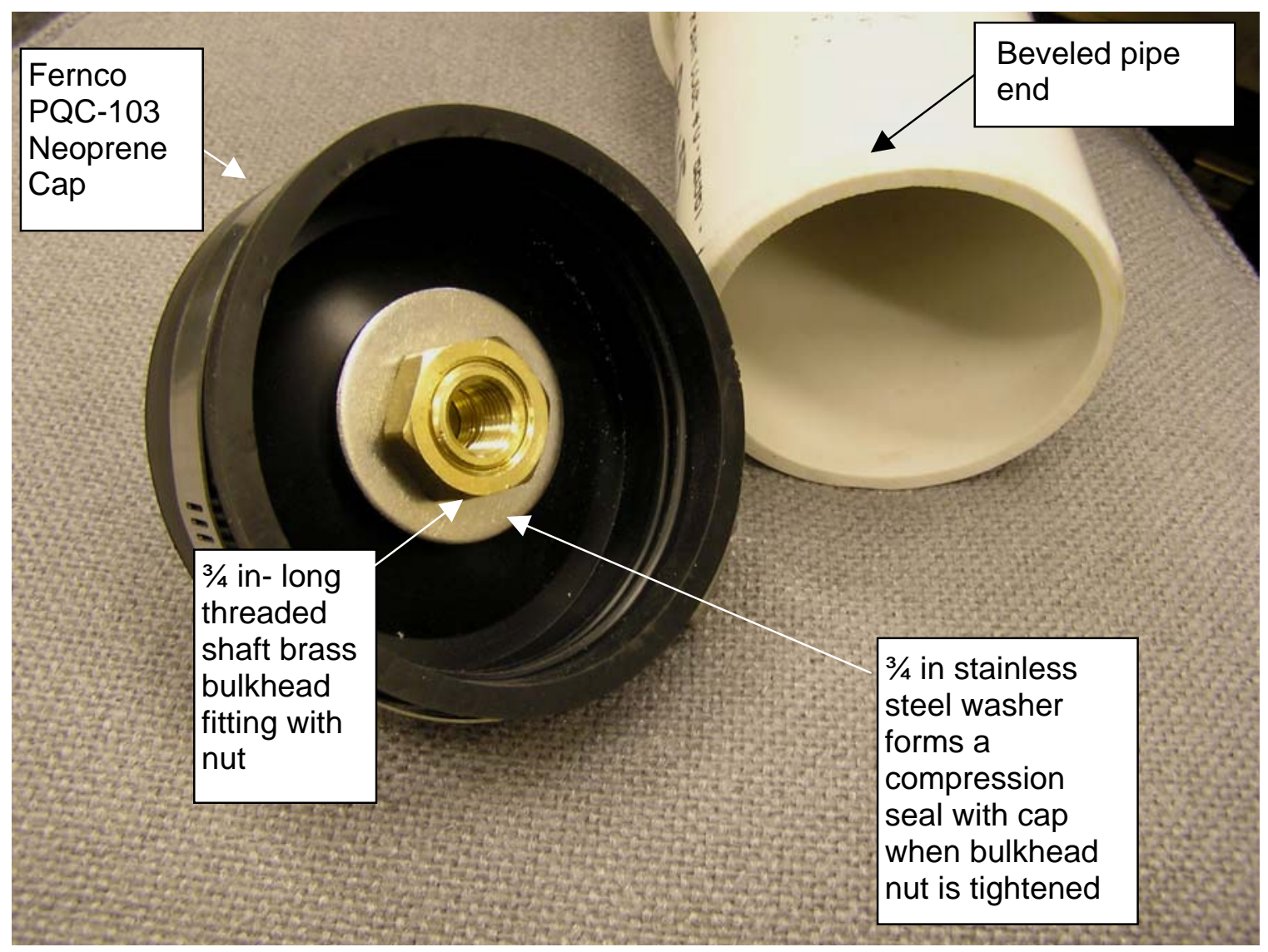


Figure 3. A one-liter capacity water trap that can be spliced into the tubing between the canister and the manometer to remove water before it reaches the manometer.

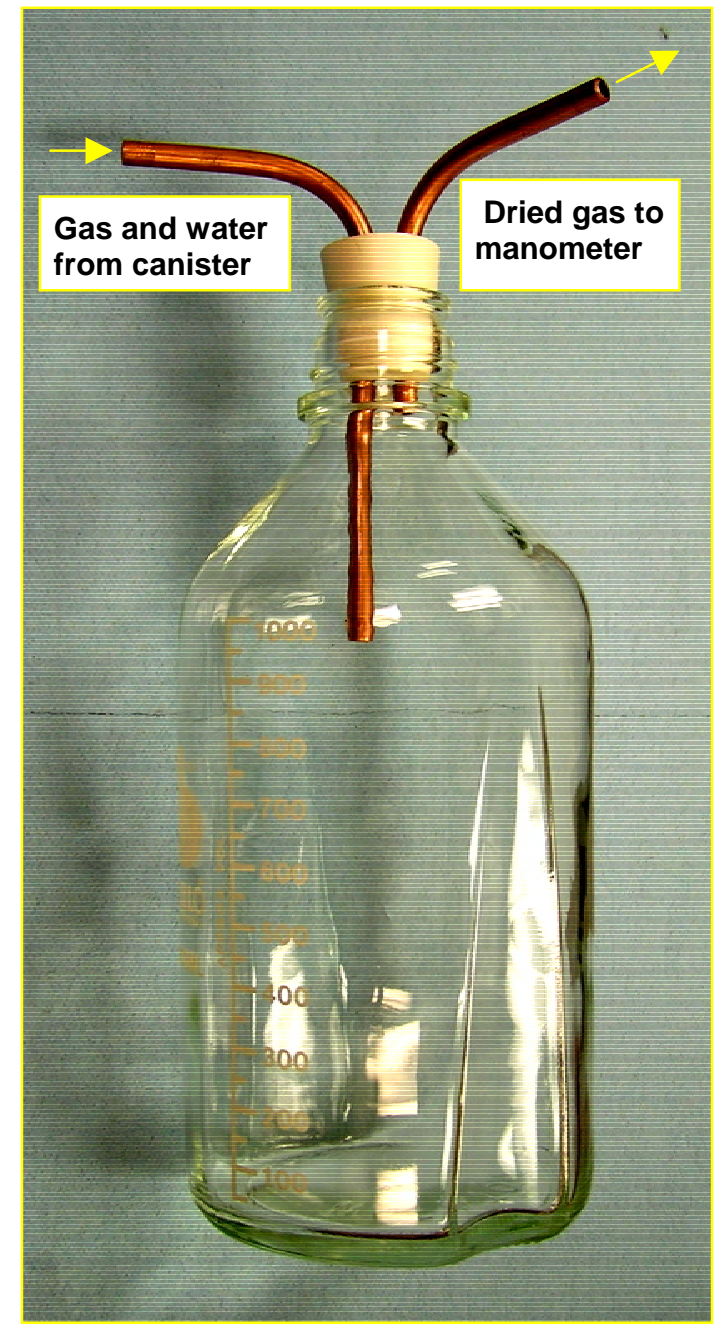


Figure 4. Design and assembly details for a system to heat zero-headspace, or other types of coal desorption canisters, to a constant temperature during lost gas measurements. This heating pad is long enough to enclose both 3- and 4inch diameter canisters. The heating pad system is expensive and is only used on projects, like offshore drilling platforms, where space is at a premium. Water baths are a less expensive alternative method of heating multiple canisters in less-space-restricted projects.

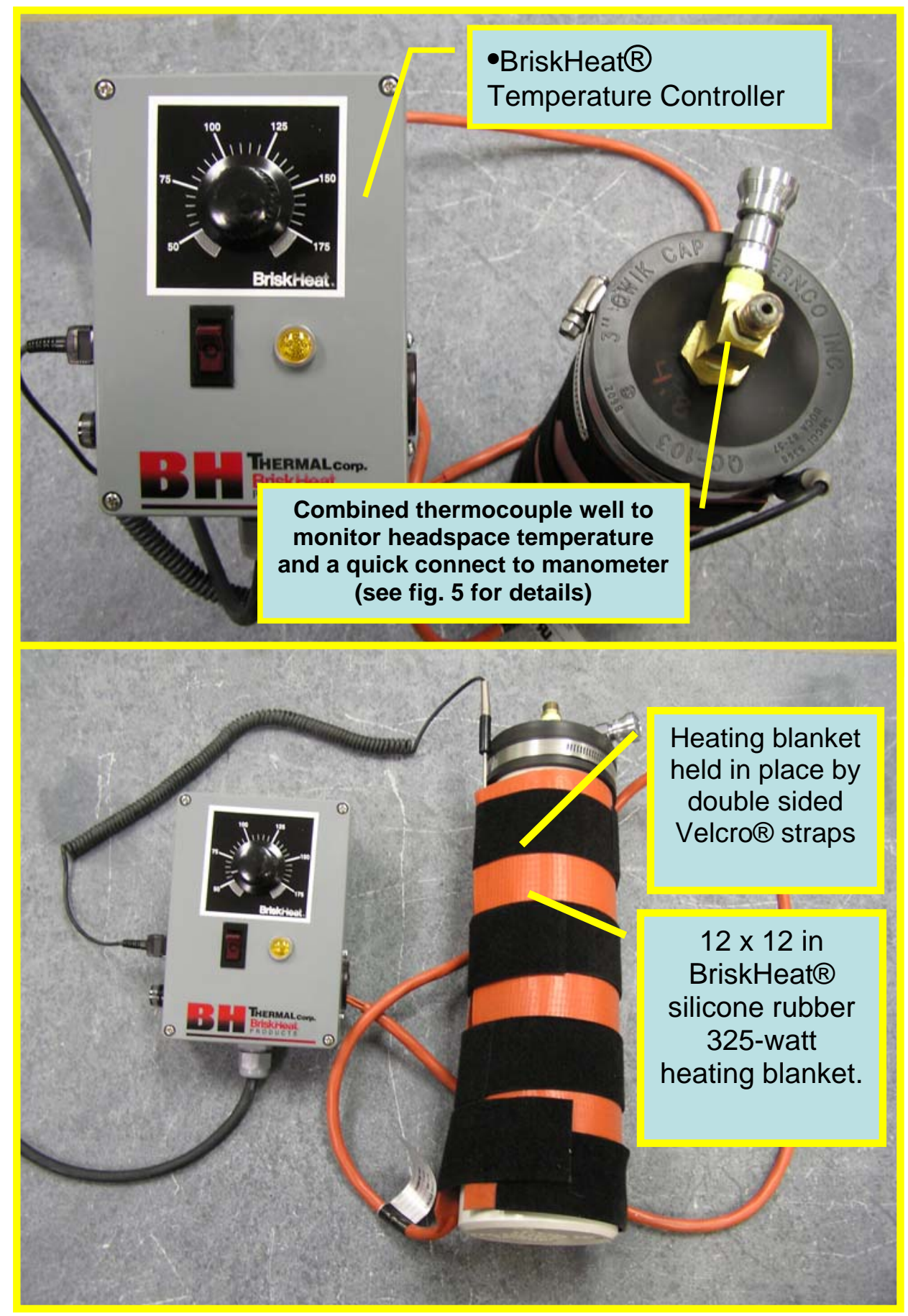


Figure 5. Design, construction, and assembly details for a Fernco® Neoprene cap fitted with a thermocouple well and quick connect. The thermocouple well for internal can measurements is not needed for zero-headspace canisters because no headspace correction is needed. Rather, the temperature measurements via the thermocouple well are used in the dry heat blanket design canister to assure that set internal desorption temperature is correct. The heat blanket thermocouple controller should remain inserted between the canister and the heater blanket as shown during the desorption experiment.

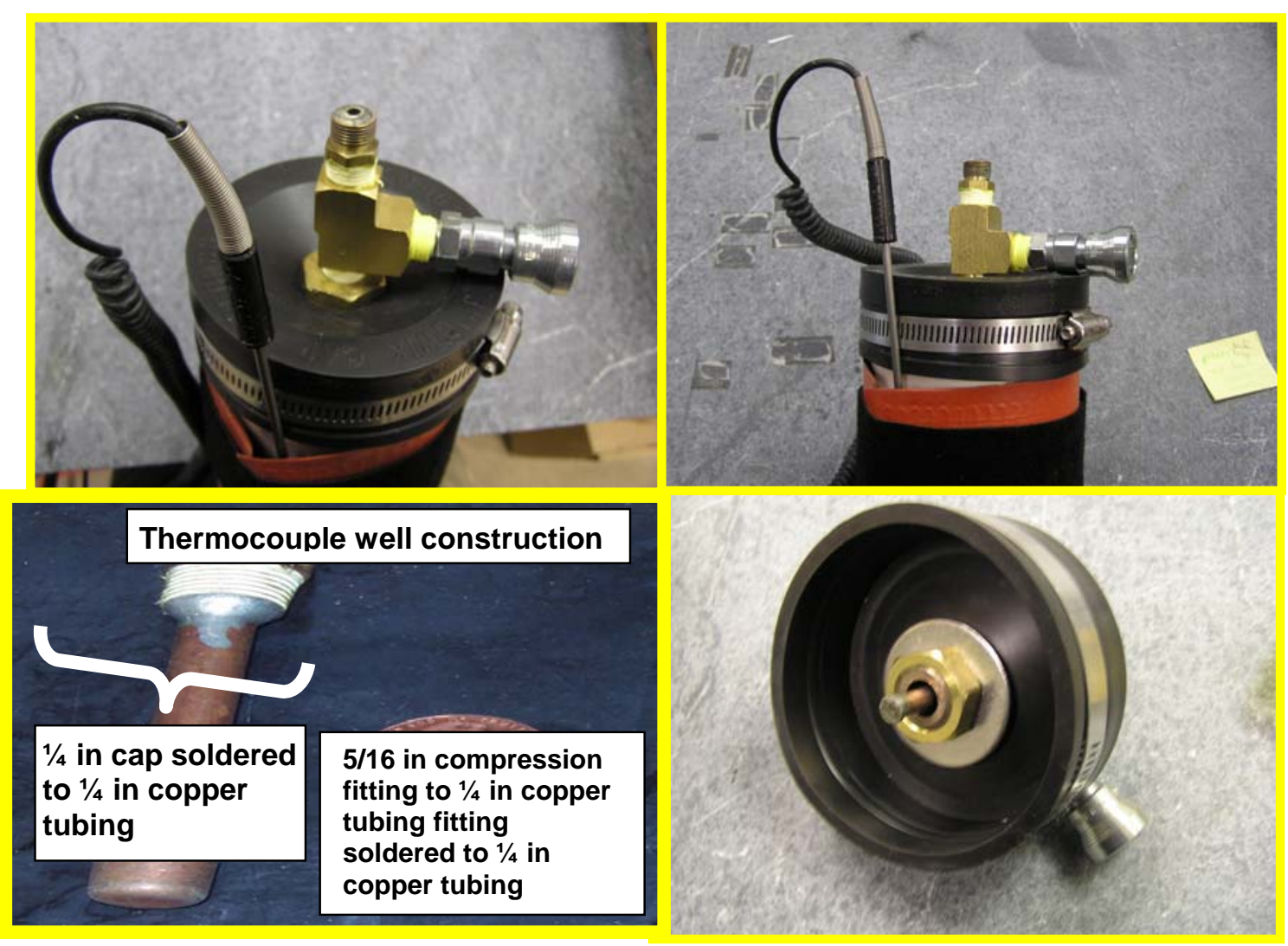

